\title{
Abdominal functional electrical stimulation to assist ventilator weaning in critical illness: a double-blinded, randomised, sham-controlled pilot study
}

Euan J. McCaughey ${ }^{1,2^{*}}$ (D) Annemijn H. Jonkman ${ }^{3}$, Claire L. Boswell-Ruys ${ }^{1,2,4}$, Rachel A. McBain ${ }^{1,2,4}$, Elizabeth A. Bye ${ }^{1,2,4}$, Anna L. Hudson 1,2, David W. Collins ${ }^{4}$, Leo M. A. Heunks ${ }^{3}$, Angus J. McLachlan ${ }^{5}$, Simon C. Gandevia ${ }^{1,2,4}$ and Jane E. Butler ${ }^{1,2}$

\begin{abstract}
Background: For every day a person is dependent on mechanical ventilation, respiratory and cardiac complications increase, quality of life decreases and costs increase by > \$USD 1500. Interventions that improve respiratory muscle function during mechanical ventilation can reduce ventilation duration. The aim of this pilot study was to assess the feasibility of employing an abdominal functional electrical stimulation (abdominal FES) training program with critically ill mechanically ventilated patients. We also investigated the effect of abdominal FES on respiratory muscle atrophy, mechanical ventilation duration and intensive care unit (ICU) length of stay.

Methods: Twenty critically ill mechanically ventilated participants were recruited over a 6-month period from one metropolitan teaching hospital. They were randomly assigned to receive active or sham (control) abdominal FES for 30 min, twice per day, 5 days per week, until ICU discharge. Feasibility was assessed through participant compliance to stimulation sessions. Abdominal and diaphragm muscle thickness were measured using ultrasound 3 times in the first week, and weekly thereafter by a blinded assessor. Respiratory function was recorded when the participant could first breathe independently and at ICU discharge, with ventilation duration and ICU length of stay also recorded at ICU discharge by a blinded assessor.

Results: Fourteen of 20 participants survived to ICU discharge (8, intervention; 6, control). One control was transferred before extubation, while one withdrew consent and one was withdrawn for staff safety after extubation. Median compliance to stimulation sessions was 92.1\% (IQR 5.77\%) in the intervention group, and 97.2\% (IQR 7.40\%) in the control group $(p=0.384$ ). While this pilot study is not adequately powered to make an accurate statistical conclusion, there appeared to be no between-group thickness changes of the rectus abdominis ( $p=0.099$ at day 3 ), diaphragm ( $p=0.652$ at day 3 ) or combined lateral abdominal muscles ( $p=0.074$ at day 3). However, ICU length of stay $(p=0.011)$ and ventilation duration $(p=0.039)$ appeared to be shorter in the intervention compared to the control group.

* Correspondence: e.mccaughey@neura.edu.au

${ }^{1}$ Neuroscience Research Australia, 139 Barker Street, Randwick, NSW 2031,

Australia

${ }^{2}$ School of Medical Sciences, University of New South Wales, Kensington,

NSW 2052, Australia

Full list of author information is available at the end of the article

(c) The Author(s). 2019 Open Access This article is distributed under the terms of the Creative Commons Attribution 4.0 International License (http://creativecommons.org/licenses/by/4.0/), which permits unrestricted use, distribution, and reproduction in any medium, provided you give appropriate credit to the original author(s) and the source, provide a link to the Creative Commons license, and indicate if changes were made. The Creative Commons Public Domain Dedication waiver (http://creativecommons.org/publicdomain/zero/1.0/) applies to the data made available in this article, unless otherwise stated. 
(Continued from previous page)

Conclusions: Our compliance rates demonstrate the feasibility of using abdominal FES with critically ill mechanically ventilated patients. While abdominal FES did not lead to differences in abdominal muscle or diaphragm thickness, it may be an effective method to reduce ventilation duration and ICU length of stay in this patient group. A fully powered study into this effect is warranted.

Trial registration: The Australian New Zealand Clinical Trials Registry, ACTRN12617001180303. Registered 9 August 2017.

Keywords: Critical illness, Electrical stimulation, Mechanical ventilation, Respiratory function, Respiratory muscles

\section{Background}

Approximately $33 \%$ of critically ill patients treated in intensive care units (ICUs) require mechanical ventilation to support respiration, some for a few hours, and others for months [1]. During this time, disuse atrophy of the major respiratory muscles, namely the diaphragm, abdominal and intercostal muscles, may occur [2]. This reduces respiratory function and leads to a range of complications including difficulty weaning from mechanical ventilation [3], increased mortality, respiratory and cardiac complications, readmissions to hospital and intensive care [2-6], and decreased quality of life [7, 8]. While a lifesaving intervention, need for mechanical ventilation is also associated with additional health care costs [9]. Interventions that reduce respiratory muscle atrophy or increase respiratory muscle strength are likely to reduce mechanical ventilation duration, with a direct impact on morbidity and mortality, quality of life and costs to the health care provider.

Functional electrical stimulation (FES) is the application of a train of electrical pulses to a motor nerve, causing the associated muscle to contract. Transcutaneous FES of the abdominal muscles, termed abdominal FES, can improve respiratory function [10-13] and assist ventilator weaning in spinal cord injury [12, 14]. Unlike inspiratory muscle training, which has been shown to improve weaning outcomes for difficult to wean patients $[15,16]$, abdominal FES does not require patient participation or cooperation [16]. A pilot study of 25 ventilated critically ill participants showed that FES of the rectus abdominis and pectoral muscles maintained respiratory muscle thickness to a greater degree than sham stimulation and shortened ICU length of stay [17]. This is despite the rectus abdominis muscles making minimal contribution to expiratory pressures $[18,19]$, and that stimulation was not applied in synchrony with respiration (increasing the risk of patient-ventilator asynchrony and increasing the load of breathing). FES of muscles in the upper legs of ventilated critically ill patients has also been shown to reduce ventilation duration [20]. Although widely advocated as an effective technique to maintain muscle mass and reduce critical illness polyneuromyopathy for critically ill patients [21, 22], it does not directly target the respiratory muscles. As the abdominal muscles play an active role in cough generation and respiration during respiratory distress [23] and we have previously shown that abdominal FES is an effective way to improve cough function [13], abdominal FES may provide a more direct, practical and efficacious way to reduce mechanical ventilation duration in critical illness. This hypothesis is further supported by the fact that respiratory muscle strength, as measured by maximum expiratory pressure (MEP) and cough peak flow (CPF), has been shown to be an independent predictor of delayed extubation, weaning success, morbidity and mortality [24, 25]. The primary aim of this pilot study was to assess the feasibility of employing an abdominal FES training program with critically ill mechanically ventilated patients. Secondary objectives were to investigate the effect of abdominal FES on muscle atrophy, mechanical ventilation duration and ICU length of stay. The data collected from this study will be used to assess feasibility and estimate sample size, for a fully powered study to ascertain whether abdominal FES can reduce mechanical ventilation in critical illness.

\section{Methods}

\section{Study design}

A double-blinded, randomised, sham-controlled pilot study was conducted in the 12 bed ICU of a metropolitan teaching hospital. The study was approved by the local research ethics board.

The aim of this pilot study was to assess the feasibility of employing an abdominal FES training program with critically ill mechanically ventilated patients. Secondary objectives were to investigate whether abdominal FES affects abdominal muscle and diaphragm thickness, respiratory function, ventilation duration, ICU length of stay and mortality in this population. Dall' Acqua et al. [17] found a medium effect (effect size $=0.75$ ) from abdominal FES on abdominal muscle thickness. Our study improves on this method by stimulating the posterolateral abdominal wall as opposed to the rectus abdominis muscles and applying stimulation in synchrony with respiration. Assuming our intervention will also have a medium effect size on abdominal muscle thickness, the optimal sample size for this pilot study is 10 participants per arm [26]. 


\section{Participants}

All consecutive admissions $(n=273)$ between 1 November 2017 and the 12 April 2018 were screened against the eligibility criteria (Fig. 1). Patients were eligible if they were $\geq 18$ years of age and dependent on mechanical ventilation due to critical illness. Patients were excluded if they were expected to be ventilated for $<24 \mathrm{~h}$ or already ventilated for $>72 \mathrm{~h}$, were pregnant, had nonpharmacological paralysis (e.g. spinal cord injury), had physical obstacles that prevent abdominal FES (e.g. abdominal trauma, pacemaker), had a diagnosed terminal illness, had no response to abdominal FES (e.g. lower motor neuron impairment or obese) or had abdominal surgery within 4 weeks prior to potential inclusion.
Similar criteria were used in a previous trial of the effectiveness of FES of the quadriceps to reduce critical illness polyneuromyopathy in critically ill mechanically ventilated patients [22].

\section{Stimulation}

Twenty participants were randomised to receive active (intervention) or sham (control) abdominal FES (Table 1). Participants received the first session of their allocated intervention $\sim 48 \mathrm{~h}$ post initiation of mechanical ventilation (enabling washout of neuromuscular blocking agents). The set up for both groups was identical, with the only difference being the stimulation parameters. Stimulation was applied for $30 \mathrm{~min}$, twice per

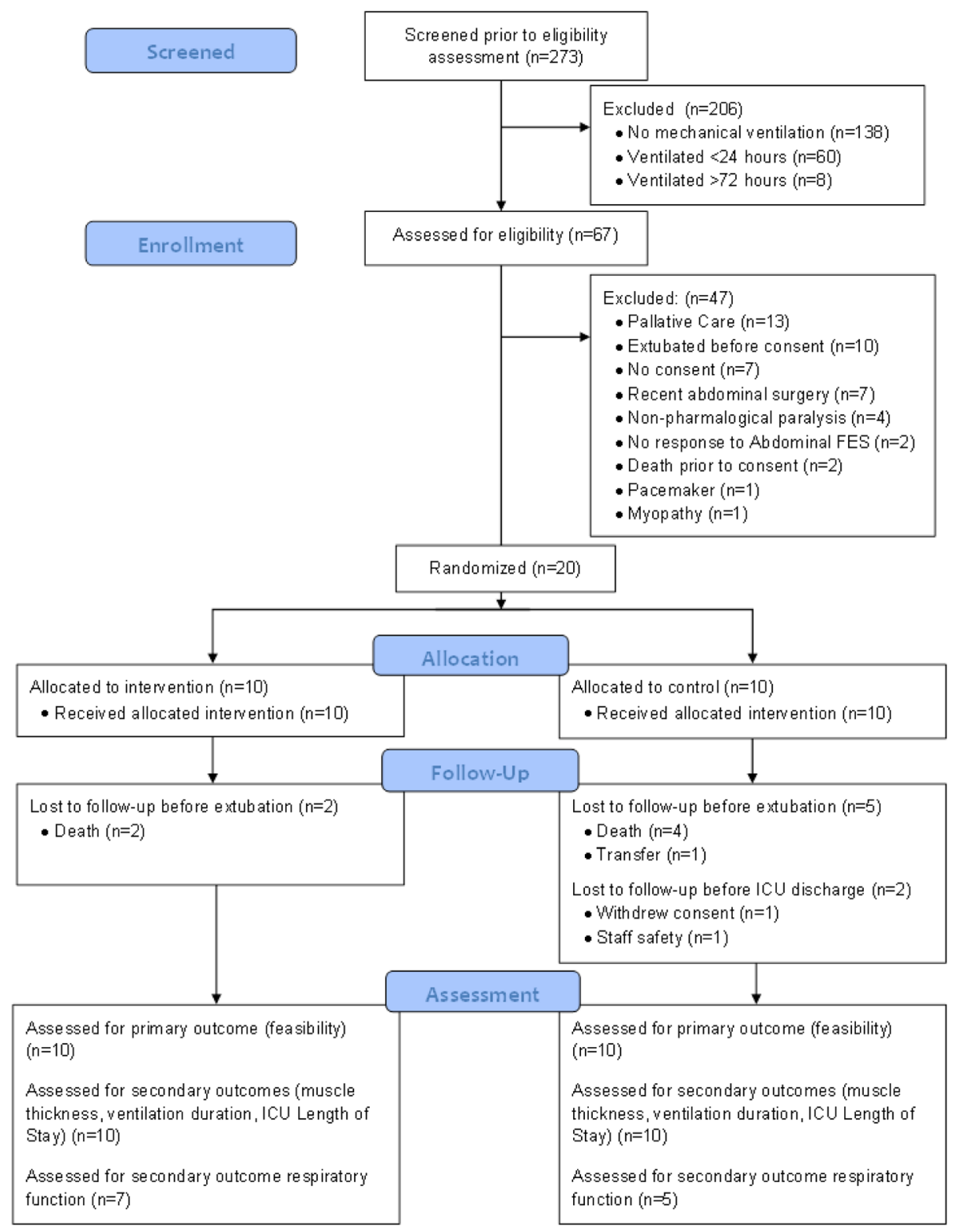

Fig. 1 Consort flow diagram of patients admitted to the intensive care unit (ICU) and the randomisation process 
Table 1 Participant information. All ventilator settings refer to first day of study. APACHE III score was calculated in the first $24 \mathrm{~h}$ of ICU admission as described by Knaus et al. [27]. PEEP positive end-expiratory pressure, $\mathrm{FiO}_{2}$ fraction of inspired oxygen, IQR interquartile range

\begin{tabular}{|c|c|c|}
\hline & $\begin{array}{l}\text { Active } \\
(n=10)\end{array}$ & $\begin{array}{l}\text { Control } \\
(n=10)\end{array}$ \\
\hline $\begin{array}{l}\text { Age (years) } \\
\text { [median (IQR)] }\end{array}$ & $56.5(18.50)$ & $61.0(17.25)$ \\
\hline $\begin{array}{l}\text { Gender } \\
{[M / F]}\end{array}$ & $7 / 3$ & $5 / 5$ \\
\hline \multicolumn{3}{|l|}{ Severity of illness at ICU admission } \\
\hline APACHE III score [median (IQR)] & $81.5(37.75)$ & $82.0(14.00)$ \\
\hline \multicolumn{3}{|l|}{ Diagnostic category at admission [n (\%)] } \\
\hline Brain injury & $6(60 \%)$ & $2(20 \%)$ \\
\hline Sepsis/septic shock & 0 & $3(30 \%)$ \\
\hline Respiratory failure & 0 & $2(20 \%)$ \\
\hline Trauma & 0 & 0 \\
\hline Post-surgical & $1(10 \%)$ & 0 \\
\hline Meningitis & $1(10 \%)$ & $1(10 \%)$ \\
\hline Other & $2(20 \%)$ & $2(20 \%)$ \\
\hline \multicolumn{3}{|l|}{ Baseline ventilation characteristics } \\
\hline \multicolumn{3}{|l|}{ Mode of ventilation $[n(\%)]$} \\
\hline Synchronized intermittent-mandatory ventilation & $10(100 \%)$ & $9(90 \%)$ \\
\hline Adaptive pressure ventilation & 0 & $1(10 \%)$ \\
\hline PEEP $\left(\mathrm{cmH}_{2} \mathrm{O}\right)$ [median (IQR)] & $10.0(3.50)$ & $10.0(2.25)$ \\
\hline $\mathrm{FiO}_{2}(\%)[$ median (IQR)] & $25.0(6.75)$ & $30.0(10.00)$ \\
\hline $\begin{array}{l}\text { Exposure to intervention (min) } \\
\text { [median (IQR)] }\end{array}$ & 366 (293.8) & 555 (492.5) \\
\hline
\end{tabular}

day, 5 days per week (including first 5 days consecutively), until discharge from the ICU, via surface electrodes $(5 \mathrm{~cm} \times 10 \mathrm{~cm}$ rectangular, UF2040, Axelgaard, USA). Electrodes were placed posteriorlaterally over the abdominal wall designed to activate the transversus abdominis and internal and external oblique muscles as previously described [18]. Stimulation was applied during exhalation using a commercially available abdominal FES device (Empi Continuum, Empi Inc., USA) with automatic synchronisation with the participant's breathing achieved using an investigational device (VentFree VF03-K, Liberate Medical LLC, USA, note not approved for therapeutic use) connected between the y-piece of the mechanical ventilator and the endotracheal tube. The active group received abdominal FES at an intensity that caused a strong visible muscle contraction (median $60 \mathrm{~mA}$ [range 50-65 $\mathrm{mA}]$ ), with a frequency of $30 \mathrm{~Hz}$ and a pulsewidth of $350 \mu$ s. The stimulation current in the control group was set at $10 \mathrm{~mA}$ (possible sensation but no muscle contraction), with a frequency of $10 \mathrm{~Hz}$ and a pulsewidth of $350 \mu \mathrm{s}$. Similar training protocols have been used in other studies performed by the research team $[11,12,14]$.

To achieve blinding, the researcher administering abdominal FES drew each participant's bedside curtain while preparing the device. This person did not perform any outcome measurements. The machine was covered with a towel or sheet, and the participants' abdomen covered with a bed sheet so that participants, family members and caregivers could not see the machine or whether stimulation resulted in muscle contractions. Outcome assessors were never in the room when stimulation was delivered. Although participants were not informed of their randomisation allocation, they could notice the contractions caused by abdominal FES (compared to the control) and therefore could become aware of the allocation. Participants were instructed not to discuss their perception of allocation with outcome assessors, other participants or clinical staff.

\section{Data collection}

Ultrasound was performed at the end of exhalation (without stimulation) to measure the thickness of the rectus abdominis, internal and external oblique and transversus abdominis muscles and diaphragm before the first abdominal FES session, twice more in the first week of participation, and then weekly until ICU discharge. All measurements were taken from muscles on the right-hand side of the participant by the same 
assessor at all assessment sessions. To measure the rectus abdominis, the probe was firstly placed on the midline of the abdomen, $2 \mathrm{~cm}$ above the umbilicus to identify the linea alba. The probe was then moved laterally until the right rectus abdominis muscle became visible, with the probe then moved in the cranial and caudal directions until the maximum thickness of the muscle was identified. From the position of the rectus abdominis, the probe was moved to the right until the lateral abdominal muscles became visible, and moved laterally until the upper and lower limits of each muscle were parallel to each other. This was approximately at the anterior axillary line. Minimal pressure to the skin was applied during these measurements to limit muscle deformation. For the diaphragm, the probe was placed parallel to the anterior axillary line in the intercostal space between the 9th and 10th rib and moved in the cranial and caudal directions until the pleural line was identified. From this point, the probe was moved approximately 1 or 2 intercostal spaces lower to identify the costal diaphragm in the zone of apposition. In all measurements the, probe was placed perpendicular to the skin.

Respiratory function was measured via forced vital capacity (FVC), forced expiratory volume in $1 \mathrm{~s}\left(\mathrm{FEV}_{1}\right)$, peak expiratory flow (PEF), maximum inspiratory pressure (MIP) and maximum expiratory pressure (MEP), as soon as possible after the participant was able to breathe independently. FVC, FEV 1 and PEF were measured with a handheld spirometer (One Flow FVC Memo, Clement Clarke International, UK) by asking the participant to exhale as fully and as forcefully as possible (verbal encouragement provided) from total lung capacity. MIP and MEP were measured using a hand-held pressure meter (MicroRPM, Vyaire Medical, USA), with participants inhaling and exhaling as fully and as forcefully as possible (verbal encouragement provided) against an occluded airway from residual volume and total lung capacity, respectively. The size of the filter approved for use with our mouth pressure device was not compatible with the tracheostomies being used at the study site. As such, MIP and MEP were not recorded from patients with tracheostomies. All measurements were recorded with the participant supine. When possible, each measurement was repeated until three reproducible results within $5 \%$ were registered, and the greatest value used for analysis [28].

Ventilation duration (defined as the total number of days from the onset of ventilation until the first successful extubation of more than $48 \mathrm{~h}$ during ICU stay [22]) and ICU length of stay (the number of days from ICU admission to ICU discharge) were obtained via chart review by a blinded assessor at ICU discharge, while mortality was obtained from the participants' medical record by the same blinded assessor 6 weeks post ICU discharge. Participants without a tracheostomy were extubated by progressively reducing ventilator support. Here, ventilator rate, pressure support, and positive endexpiratory pressure (PEEP) were decreased while respiratory rate, respiratory effort, tidal volume and blood gases were monitored. When support reached low levels, typically PEEP and pressure support of 8 and $7 \mathrm{cmH}_{2} \mathrm{O}$, respectively, participants were extubated based on clinical judgement. Participants with a tracheostomy were weaned from ventilatory support via a similar scheme and then progressive ventilator-free breathing.

\section{Analysis}

Categorical data are summarised in terms of the number of participants with data at the relevant time point $(n)$ and as a percentage of all participants. Continuous data are expressed as median and interquartile range (IQR), or mean and standard deviation unless otherwise stated. Compliance is the number of sessions completed as a percentage of all sessions that should have been completed between randomisation and completion or withdrawal and is considered a continuous variable. In cases where participants underwent a double session (i.e. one 60-min session instead of two 30-min sessions), this was regarded as compliant and taken as two completed sessions for analysis purposes. A Mann-Whitney $U$ test was used to compare compliance between groups. The combined thickness of the internal and external oblique and transversus abdominis muscles (i.e. from the upper fascia of the external oblique to the lower fascia of the transversus abdominis) was also analysed to increase accuracy, with this measurement referred to here as the combined lateral abdominal muscles. The mean of at least three ultrasound images for each muscle group at each assessment session was used for analysis. Blinded researchers in another country also checked the marked images to verify correct muscle identification and marker placement. In cases of disagreement, where the fascia was not clear in saved images, or the correct muscle group was not obvious, the data were excluded (18.2\% [ $n=14], 27.3 \%$ [ $n=21]$, and $22.1 \%$ [ $n=17$ ] of sessions were excluded for the rectus abdominis, combined lateral abdominal muscles and diaphragm, respectively). Change from baseline of rectus abdominis, combined lateral abdominal, internal and external oblique and transversus abdominis muscles and diaphragm thickness were treated as continuous variables and analysed using a linear mixed effects model with fixed factors of baseline thickness, treatment, assessment session and treatment by assessment session interaction, and a random effect of participant (change from baseline thickness $\sim$ baseline thickness + treatment + assessment session + (treatment * assessment session) $+(1 \mid$ patient $))$ [29]. These mixed models compare the thickness of the muscles over time. 
Due to the small sample size, and the risk of a normality test being underpowered, we followed the statistical methods in Dall' Acqua et al. [17], where the distribution of muscle thickness was assumed normal.

There are no respiratory function measures for the participants who died during the study. The MannWhitney $U$ test, as a distribution-free non-parametric test, was used to analyse respiratory function data. Ventilation duration and ICU length of stay were analysed using Gray's test in the survival analysis [30], with the competing risks of death or withdrawal of treatment (e.g. ventilator support) with the intention of subsequent death. Gray's test compares cause-specific cumulative incidence curves. In the case where less than $50 \%$ of participants achieved the outcome, due to either competing events or censoring, the median time to the outcome was not estimable. The sample size required for a larger study was also calculated based on survival test and cause-specific hazard approach accounting for competing events. All analyses were performed using SPSS (Version 22, IBM Corp, NY, USA).

\section{Results}

\section{Study population and compliance}

Twelve males and eight females, with a median age of 56.5 years in the active group and 61.0 years in the control group, were recruited for this study (Table 1). Fourteen patients survived to ICU discharge (8 active, 6 control). One control participant was transferred to another hospital before extubation. After extubation, one further control participant withdrew consent and one was withdrawn due to violent behaviour. The median time on mechanical ventilation before starting the intervention was 1.5 days (IQR 1 day). The median time on the study for participants who died was 11.5 days (IQR 13.25 days). Median compliance for the training sessions was $92.1 \%$ (IQR $5.77 \%$ ) in the active group and $97.2 \%$ (IQR 7.40\%) in the control group ( $p=0.384)$, with active participants having a median exposure to the intervention of $366 \mathrm{~min}$ (IQR $293.8 \mathrm{~min}$ ) and control participants $555 \mathrm{~min}$ (IQR $492.5 \mathrm{~min}$ ) (Table 1).

\section{Adverse events}

There were eight non-serious adverse events in the active group and 14 in the control group and two serious adverse events (death) in the active group and eight in the control group (four death, three cardiac events, one re-intubation) (Table 2). Only one participant, who was a control, suffered multiple serious adverse events (2 cardiac events and death). For adverse events, two active participants experienced three events (2 hospital-acquired infections and pneumonia; 2 hospital-acquired infections and tracheostomy), and one had one adverse event and a serious adverse event (blocked pressure drain and death). In the control group, one participant experienced four adverse events (2 hospital-acquired infections, pneumonia and tracheostomy), two had three adverse events and a serious adverse event (high respiratory rate, hospital-acquired infection, diarrhoea and serious cardiac event; 2 hospital-acquired infections, laparotomy and reintubation) and one experienced an adverse event and serious adverse event (poor wound healing and death). All other adverse or serious adverse events were experienced by individual participants. An independent safety data monitoring committee judged that none of the serious adverse events were related to the intervention.

\section{Muscle atrophy}

There was no difference in the longitudinal changes from baseline in the thickness of rectus abdominis, diaphragm and combined lateral abdominal muscles between groups at any assessment sessions (Table 3). Further analyses were also conducted on each individual muscle within the combined lateral abdominal muscles, where there did appear to be a change in the thickness

Table 2 Adverse events stratified by group. Serious adverse events and non-serious adverse events are reported separately. All data are reported as absolute number of events, as well as the proportion of all serious adverse or non-serious adverse events per group. While some participants experienced multiple adverse events (see the "Results" section: "Adverse events"), none of the adverse events reported here were deemed to be related to the intervention

\begin{tabular}{lll}
\hline & Active & Control \\
\hline Serious adverse events & $2(100 \%)$ & $4(50 \%)$ \\
Death & 0 & $3(37.5 \%)$ \\
Serious cardiac events & 0 & $1(12.5 \%)$ \\
Respiratory failure requiring reintubation & 2 & 8 \\
Total & & \\
Non-serious adverse events, $n$ (\%) & $4(50 \%)$ & $6(42.9 \%)$ \\
Hospital-acquired infection & $1(12.5 \%)$ & $1(7.1 \%)$ \\
Tracheostomy & $1(12.5 \%)$ & 0 \\
Blocked intracranial pressure drain & $1(12.5 \%)$ & 0 \\
Headache & $1(12.5 \%)$ & 0 \\
Pneumonia & 0 & $1(7.1 \%)$ \\
Diarrhoea & 0 & $1(7.1 \%)$ \\
Gout & 0 & $1(7.1 \%)$ \\
High respiratory rate & 0 & $1(7.1 \%)$ \\
Laparotomy & 0 & $1(7.1 \%)$ \\
Cardiac event & 0 & $1(7.1 \%)$ \\
Poorly healing surgical wound & 0 & $1(7.1 \%)$ \\
Violence to staff & 8 & 14 \\
Total & & \\
\hline
\end{tabular}


Table 3 Group comparison of change from baseline in thicknesses of rectus abdominis, diaphragm, combined lateral abdominal muscle and each individual muscle by assessment session. Data are summarised as mean \pm SD (n). Active versus control analysed using a least square mean difference based on a mixed effects model for repeated measures. $p$ values based on a mixed effects model for repeated measures. NE not estimable

\begin{tabular}{|c|c|c|c|c|}
\hline Assessment session & Active & Control & Active-control & $p$ value \\
\hline \multicolumn{5}{|c|}{ Change from baseline in rectus abdominis thickness $(\mathrm{mm})$ by assessment session } \\
\hline Day 3 & $0.33 \pm 0.909(6)$ & $-0.10 \pm 0.451(9)$ & $0.61(-0.13,1.35)$ & 0.099 \\
\hline Day 5 & $-0.03 \pm 0.871(5)$ & $0.29 \pm 0.759(6)$ & $-0.11(-0.96,0.74)$ & 0.785 \\
\hline Day 12 & $0.68 \pm 0.165(2)$ & $0.35 \pm 0.453(4)$ & $0.09(-1.07,1.25)$ & 0.877 \\
\hline Day 19 & NE & $1.22 \pm 1.167(2)$ & $\mathrm{NE}$ & NE \\
\hline Day 26 & $\mathrm{NE}$ & $1.37 \pm 0.813(2)$ & $\mathrm{NE}$ & $\mathrm{NE}$ \\
\hline Day 33 & $\mathrm{NE}$ & $2.90 \pm 0.071(2)$ & NE & $\mathrm{NE}$ \\
\hline \multicolumn{5}{|c|}{ Change from baseline in diaphragm thickness $(\mathrm{mm})$ by assessment session } \\
\hline Day 3 & $-0.17 \pm 0.274(7)$ & $-0.18 \pm 0.207(6)$ & $0.06(-0.23,0.36)$ & 0.652 \\
\hline Day 5 & $-0.11 \pm 0.404(7)$ & $-0.18 \pm 0.225(4)$ & $-0.04(-0.38,0.30)$ & 0.794 \\
\hline Day 12 & $-0.13 \pm 0.305(4)$ & $-0.03 \pm 0.336(4)$ & $-0.07(-0.44,0.31)$ & 0.698 \\
\hline Day 19 & $\mathrm{NE}$ & $0.30(1)$ & NE & $\mathrm{NE}$ \\
\hline Day 26 & $\mathrm{NE}$ & $-0.72(1)$ & $\mathrm{NE}$ & $\mathrm{NE}$ \\
\hline Day 33 & $\mathrm{NE}$ & $0.08(1)$ & $\mathrm{NE}$ & $\mathrm{NE}$ \\
\hline \multicolumn{5}{|c|}{ Change from baseline in combined lateral abdominal muscle thickness $(\mathrm{mm})$ by assessment session } \\
\hline Day 3 & $2.51 \pm 2.535(4)$ & $-0.01 \pm 2.113(9)$ & $3.05(-0.35,6.44)$ & 0.074 \\
\hline Day 5 & $0.63 \pm 0.701(4)$ & $0.28 \pm 2.186(7)$ & $1.23(-2.29,4.75)$ & 0.463 \\
\hline Day 12 & $1.55(1)$ & $-0.88 \pm 2.902(5)$ & $3.66(-1.96,9.28)$ & 0.183 \\
\hline Day 19 & NE & $0.22 \pm 3.005(2)$ & NE & $\mathrm{NE}$ \\
\hline Day 26 & NE & $4.12 \pm 4.419(2)$ & $\mathrm{NE}$ & NE \\
\hline Day 33 & $\mathrm{NE}$ & $3.75(1)$ & $\mathrm{NE}$ & $\mathrm{NE}$ \\
\hline \multicolumn{5}{|c|}{ Change from baseline in external oblique thickness $(\mathrm{mm})$ by assessment session } \\
\hline Day 3 & $0.52 \pm 0.685(4)$ & $-0.05 \pm 1.153(9)$ & $1.08(-0.07,2.23)$ & 0.064 \\
\hline Day 5 & $0.09 \pm 0.954(4)$ & $-0.35 \pm 0.881(7)$ & $0.95(-0.24,2.13)$ & 0.108 \\
\hline Day 12 & $-1.14(1)$ & $-0.49 \pm 0.248(5)$ & $-0.68(-2.57,1.20)$ & 0.450 \\
\hline Day 19 & $\mathrm{NE}$ & $0.35 \pm 0.071(2)$ & NE & NE \\
\hline Day 26 & $\mathrm{NE}$ & $0.77 \pm 0.177(2)$ & $\mathrm{NE}$ & $\mathrm{NE}$ \\
\hline Day 33 & $\mathrm{NE}$ & $2.20(1)$ & $\mathrm{NE}$ & $\mathrm{NE}$ \\
\hline \multicolumn{5}{|c|}{ Change from baseline in internal oblique thickness $(\mathrm{mm})$ by assessment session } \\
\hline Day 3 & $0.79 \pm 1.718(4)$ & $0.13 \pm 0.936(9)$ & $1.08(-1.24,3.40)$ & 0.335 \\
\hline Day 5 & $-0.43 \pm 1.040(4)$ & $0.58 \pm 1.694(7)$ & $-0.37(-2.74,2.01)$ & 0.746 \\
\hline Day 12 & $0.09(1)$ & $-0.05 \pm 2.385(5)$ & $1.61(-2.16,5.39)$ & 0.375 \\
\hline Day 19 & $\mathrm{NE}$ & $0.50 \pm 1.838(2)$ & $\mathrm{NE}$ & $\mathrm{NE}$ \\
\hline Day 26 & NE & $2.33 \pm 2.722(2)$ & NE & $\mathrm{NE}$ \\
\hline Day 33 & NE & $1.75(1)$ & NE & NE \\
\hline \multicolumn{5}{|c|}{ Change from baseline in transversus abdominis thickness $(\mathrm{mm})$ by assessment session } \\
\hline Day 3 & $0.85 \pm 1.065(4)$ & $-0.12 \pm 0.849(9)$ & $1.04(0.10,1.98)$ & 0.032 \\
\hline Day 5 & $0.56 \pm 0.775$ & $0.10 \pm 0.532(7)$ & $0.68(-0.32,1.68)$ & 0.168 \\
\hline Day 12 & $1.74(1)$ & $-0.11 \pm 0.318$ & $2.28(0.50,4.06)$ & 0.016 \\
\hline Day 19 & $\mathrm{NE}$ & $-0.18 \pm 0.742(2)$ & $\mathrm{NE}$ & $\mathrm{NE}$ \\
\hline Day 26 & $\mathrm{NE}$ & $0.78 \pm 1.025$ & $\mathrm{NE}$ & NE \\
\hline Day 33 & $\mathrm{NE}$ & $0.35(1)$ & NE & $\mathrm{NE}$ \\
\hline
\end{tabular}


of the transversus abdominis at day $3(0.85$ vs. -0.12 , $p=0.032$ ). It should be noted that the results for assessment sessions beyond day 5 were not stable or not estimable due to the small or no sample sizes.

\section{Respiratory function}

Respiratory function was assessed at a median of 6 days (IQR 3 days) from randomisation for the active group and 15 days (IQR 15 days) from randomisation for the control group $(p=0.084)$. In the active group, one participant was unable to perform all respiratory function measures due to delirium and one was unable to adequately perform MIP and MEP measurements due to tracheostomy. In the control group, one participant was unable to perform all respiratory measures due to transfer to another hospital and one was unable to perform MIP and MEP due to tracheostomy. There was no difference in FVC $(p=0.371), \operatorname{FEV}_{1}(p=0.371), \operatorname{MIP}(p=$ $0.762)$, MEP $(p=0.283)$ or PEF $(p=0.061)$ between groups (Table 4).

\section{Clinical outcomes}

Ventilation duration (median 6.5 versus 34 days, Gray's test $p=0.039$ ) and ICU length of stay (median 11 versus not estimable days, Gray's test $p=0.011$ ) were shorter in the active compared to the control group (Fig. 2). Of the 13 participants liberated from mechanical ventilation, nine (69.2\%, 6 active, 3 control) were liberated by reducing ventilator support. The four remaining participants (two active, two control) were extubated via progressive ventilator-free breathing. The median time from initiation of progressive ventilator-free breathing to extubation was 9.5 days (IQR 7.75 days).

There was no difference in mortality between groups $(p=0.629)$.

\section{Discussion}

The aim of this pilot study was to assess the feasibility of employing an abdominal FES training program with critically ill mechanically ventilated patients. We also investigated the effect of abdominal FES on respiratory muscle atrophy, mechanical ventilation duration and ICU length of stay. Our compliance to the stimulation sessions of $>90 \%$ in both groups demonstrates the feasibility of applying this intervention in the critically ill mechanically ventilated population. While this pilot study is not adequately powered to make an accurate statistical conclusion, we did not find a longitudinal difference in respiratory muscle thickness between groups. However, ICU length of stay and duration of mechanical ventilation duration were shorter in the abdominal FES than the control group. This provides justification for a fully powered study to determine whether abdominal FES can reduce mechanical ventilation in critical illness. Such a study would require 254 participants (based on a cause-specific hazard approach accounting for competing events, assuming $60 \%$ of intervention and $45 \%$ of controls being liberated from the ventilator by day 9 , logrank test ( 2 sided), $\alpha=0.05$ (two sided), $\beta=0.1$, mortality at day $9=20 \%, 10 \%$ loss to follow-up).

Routsi et al. [22] demonstrated that participants who received FES of the quadriceps had a ventilation duration of 7 days compared to 10 days for controls $(p=$ 0.07). Abu-Khaber et al. [20] found the same technique reduced ventilation duration from 12 to 9 days in a similar group of patients $(p=0.048)$. However, while advocated clinically as a way to reduce ventilation duration $[21,22]$, this technique does not directly target the respiratory muscles. Here, we found abdominal FES appeared to reduce ventilation duration and ICU length of stay. In agreement, Dall'Acqua et al. [17] found that FES of the rectus abdominis and intercostal muscles reduced ICU length of stay $(p=0.045)$. In contrast, Routsi et al. [22] found that FES of the quadriceps did not change ICU length of stay $(p=0.11)$. With each ICU bed day in Australian public hospitals estimated at \$A6141 (compared to $\$ A 2351$ for a general ward bed) [31], a reduction in ICU length of stay would result in a significant cost saving for local health care providers. As such, abdominal FES may offer a useful clinical addition or

Table 4 Respiratory function. Respiratory function is analysed as soon as possible after the participant is able to breathe independently. There are no respiratory function measures for the six participants who died during the study. See the section "Analysis" for further information relating to who participated in respiratory function measurements. Analysis was performed using the Mann-Whitney $U$ test. All data are shown as: Median (interquartile range (IQR)) [number of participants providing data (N)]. MIP maximum inspiratory pressure, MEP maximum expiratory pressure, PEF peak expiratory flow, FVC forced vital capacity, FEV f forced exhaled volume in $1 \mathrm{~s}$

\begin{tabular}{llll}
\hline & Active (median (IQR) $[N])$ & Control (median (IQR) $[N])$ & $p$ value \\
\hline MIP $\left(\mathrm{cmH}_{2} \mathrm{O}\right)$ & $29.0(26.75)[N=6]$ & $32.5(9.50)[N=4]$ & 0.762 \\
MEP $\left(\mathrm{cmH}_{2} \mathrm{O}\right)$ & $35.5(12.75)[N=6]$ & $26.0(4.00)[N=4]$ & 0.283 \\
PEF $(\mathrm{L} / \mathrm{min})$ & $127.5(62.5)[N=7]$ & $50.0(55.00)[N=5]$ & 0.061 \\
FVC $(\mathrm{L})$ & $1.3(0.58)[N=7]$ & $0.9(0.90)[N=5]$ & 0.371 \\
FEV ${ }_{1}(\mathrm{~L})$ & $0.9(0.48)[N=7]$ & $0.6(0.70)[N=5]$ & 0.371 \\
\hline
\end{tabular}



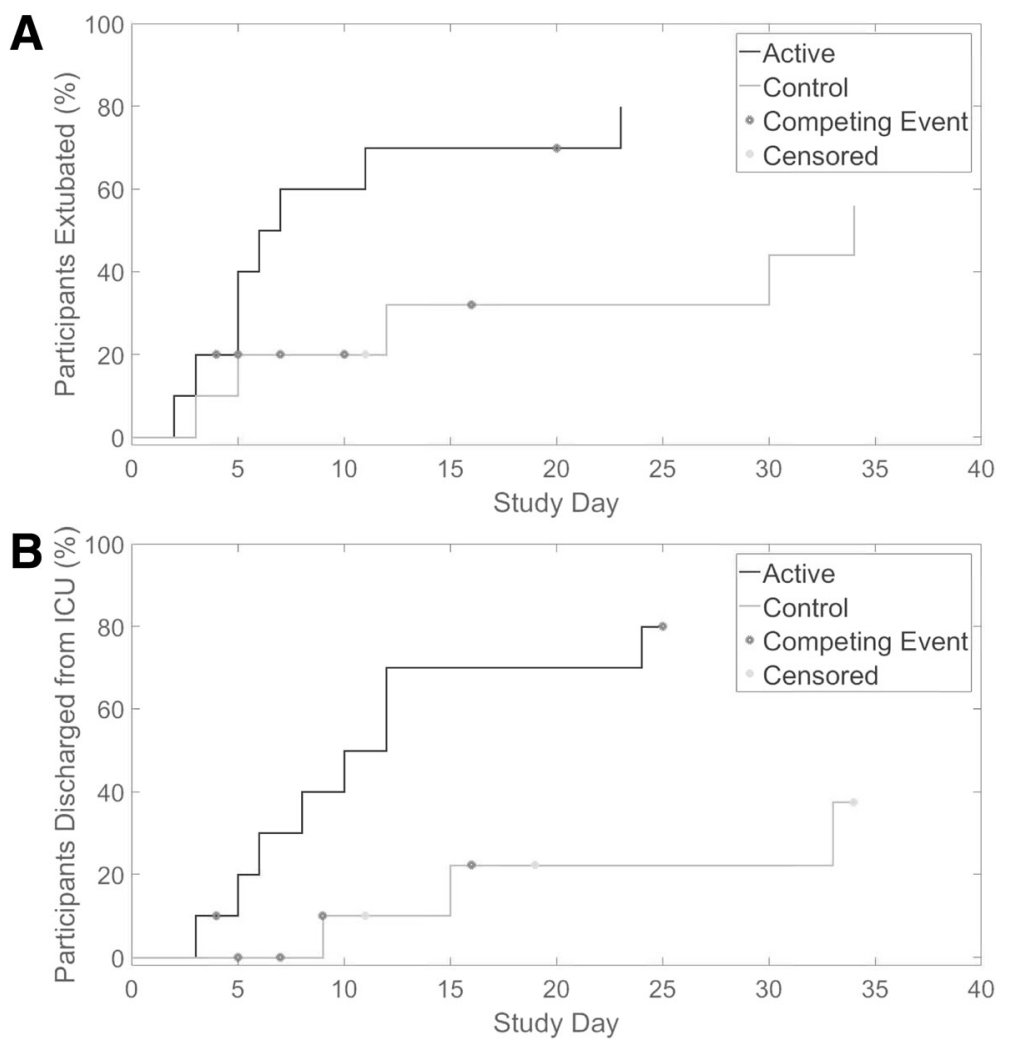

Fig. 2 Cumulative incidence curves for mechanical ventilation duration (a) and intensive care unit (ICU) length of stay (b). Fourteen participants survived to ICU discharge (8 active (dark grey), 6 control (light grey)). One control participant was transferred to another hospital before extubation and as such was censored from both the ventilation duration and ICU length of stay analysis. After extubation, one control participant withdrew consent and one was withdrawn due to threatening behaviour, both were censored from the ICU length of stay analysis. Competing events were death or withdrawal of treatment (e.g., ventilator support) with the intention of subsequent death (marked with a dark grey asterisk). Participants who were censored are represented by a light grey asterisk. ICU intensive care unit

alternative to FES of the quadriceps and is worthy of further exploration.

Our finding that there appeared to be no longitudinal change in the thickness of the rectus abdominis muscles in either the intervention or control group is in contrast to Dall'Acqua et al. [17], who found no change in rectus abdominis thickness in patients who received FES of the rectus abdominis and intercostal muscles, but a significant $16.3 \%$ decrease in the control group. This, coupled with the fact that we did not observe a difference in diaphragm thickness between the groups, may indicate that the mechanisms of abdominal FES to reduce ventilation duration are not solely based on muscle thickness. Furthermore, MIP and MEP are good indicators of respiratory muscle strength. [32] While these outcomes and those of lung function were not different between the two groups, a previous systematic review has shown that abdominal FES can improve respiratory function in spinal cord injury [13]. Further study of the effect of abdominal FES on respiratory function in this population is warranted.

Our average recruitment rate of 4 participants per month was higher than expected and shows the feasibility of a larger study, particularly if it were multi-institutional. However, $12.6 \%$ of all interventions in this study were double sessions (stimulation applied for 1 consecutive hour, as opposed to two 30-min sessions), largely due to staffing issues and difficulty accessing participants (e.g. they were away for a procedure). This suggests that one training session per day may be more practical for a follow-up study. The mortality rate in this study $(30 \%)$ was slightly lower than that in a larger study by Routsi et al. (35\%) that employed the same inclusion and exclusion criteria [22], but is in line with large epidemiological studies of ICU patients [33].

\section{Limitations}

While ultrasound has been shown to be a reliable measure of diaphragm thickness in the ICU [34], ultrasound measurements of the abdominal muscles and diaphragm recorded here had large intra- and inter-participant variability. This may have been due, at least in part, to a number of these critically ill patients having fluid overload, large amounts of oedema and high intra-abdominal pressures, or a combination of all three. This could have 
led to changes in muscle architecture unrelated to atrophy or abdominal FES. However, it should be noted that fluid imbalance alone has been shown not to affect diaphragm thickness [34, 35]. Difficulty with the ultrasound measurements led to a number of sessions having to be excluded from the analysis. As a result, more robust methods are needed to measure respiratory muscle thickness in a large clinical trial.

The majority of the analysis in this pilot study was affected by post-randomisation events and effects, particularly death. This was only accounted for in the analysis of ventilation duration and ICU length of stay, which employed Gray's test with death and withdrawal of treatment treated as competing events or censoring. As such, there may be some bias in the other outcome measures due to the larger number of control participants not completing the study. Analysis of a larger study will need to account for these post-randomisation events in all outcome measures.

\section{Conclusion}

This pilot study demonstrates the feasibility of employing an abdominal FES training program with critically ill mechanically ventilated patients. While there were no longitudinal changes in respiratory muscle thickness between groups, participants who received abdominal FES had a shorter mechanical ventilation duration and ICU length of stay. A fully powered study into this effect is now warranted, with a positive outcome likely to lead to the rapid clinical translation of this technique. This should lead to reduced morbidity and mortality, improved quality of life and a significant cost saving for the health care provider.

\section{Abbreviations}

FES: Functional electrical stimulation; FEV ${ }_{1}$ : Forced exhaled volume in $1 \mathrm{~s}$; $\mathrm{FiO}_{2}$ : Fraction of inspired oxygen; FVC: Forced vital capacity; ICU: Intensive care unit; IQR: Interquartile range; MEP: Maximum expiratory pressure; MIP: Maximum inspiratory pressure; PEEP: Positive end-expiratory pressure; PEF: Peak expiratory flow

\footnotetext{
Acknowledgements

The authors would like to thank John Shen and Jason Cai from OcTech Medical for their statistical contribution to the project and review of the final manuscript. The authors would also like to thank Mr. Kamal Aryal, ICU Research Manager, for his assistance in coordinating outcome reporting. Finally, we would also like to thank all of the clinicians and staff in the ICU for their assistance in screening patients and the Safety and Data Monitoring Committee for their assistance in monitoring this trial.
}

\section{Authors' contributions}

EJM, SCG, AJM and JEB came up with the study concept. All authors developed the study design and protocol. EJM, CBR, RAM and ELB collected the study data. All authors were involved in the analysis and interpretation of data. EJM prepared the first draft of the manuscript. All co-authors provided input and critical review of the manuscript leading to the final version. All authors read and approved the final manuscript.

\section{Funding}

This study was supported by grants from Liberate Medical, National Science Foundation, Kentucky Cabinet for Economic Development, the National
Health and Medical Research Council (NHMRC), The Prince of Wales Hospital Foundation (POWHF) and The Australian Academy of Technological Sciences and Engineering (ATSE). AJM from Liberate Medical assisted in the design of the trial and in reviewing the manuscript. Liberate Medical had no role in the collection of data. The NHMRC, POWHF and ATSE had no role in the design of the study; collection, analysis and interpretation of data; and writing the manuscript.

\section{Availability of data and materials}

The datasets used and analysed during the current study are available from the corresponding author on reasonable request.

\section{Ethics approval and consent to participate}

This study was approved by the South Eastern Sydney Local Health District Human Research Ethics Committee (Local Code: 17/050). As most participants were lacking the capacity to give consent, approval was granted by the New South Wales Civil and Administrative Tribunal to take consent from the 'Person Responsible' for each patient (Case Number: 2017/ 00237843).

\section{Consent for publication}

Not applicable.

\section{Competing interests}

AJM is employed by Liberate Medical LLC, a medical device company that is developing an abdominal muscle stimulator. EJM has previously received financial support from Liberate Medical LLC to conduct a systematic review [13].

\section{Author details}

${ }^{1}$ Neuroscience Research Australia, 139 Barker Street, Randwick, NSW 2031, Australia. ${ }^{2}$ School of Medical Sciences, University of New South Wales, Kensington, NSW 2052, Australia. ${ }^{3}$ Department of Intensive Care Medicine, Amsterdam UMC, Vrije Universiteit Amsterdam, De Boelelaan, 1117 Amsterdam, The Netherlands. ${ }^{4}$ Prince of Wales Hospital, Randwick, NSW 2031, Australia. ${ }^{5}$ Liberate Medical LLC, 6400 Westwind Way, Suite A, Crestwood, KY 40014, USA.

Received: 1 November 2018 Accepted: 16 July 2019

Published online: 24 July 2019

\section{References}

1. Esteban A, Anzueto A, Frutos F, Alia I, Brochard L, Stewart TE, et al. Characteristics and outcomes in adult patients receiving mechanical ventilation: a 28-day international study. JAMA. 2002;287(3):345-55.

2. Schellekens WJM, van Hees HWH, Doorduin J, Roesthuis LH, Scheffer GJ, van der Hoeven JG, et al. Strategies to optimize respiratory muscle function in ICU patients. Crit Care. 2016;20(1):103.

3. Larsson L, Friedrich O. Critical illness myopathy (CIM) and ventilator-induced diaphragm muscle dysfunction (VIDD): acquired myopathies affecting contractile proteins. Compr Physiol. 2016;7(1):105-12.

4. Cook DJ, Walter SD, Cook RJ, Griffith LE, Guyatt GH, Leasa D, et al. Incidence of and risk factors for ventilator-associated pneumonia in critically ill patients. Ann Intern Med. 1998;129(6):433-40.

5. Klompas M, Khan Y, Kleinman K, Evans RS, Lloyd JF, Stevenson K, et al. Multicenter evaluation of a novel surveillance paradigm for complications of mechanical ventilation. PLoS One. 2011;6(3):e18062.

6. Mutlu GM, Mutlu EA, Factor P. Gl complications in patients receiving mechanical ventilation. Chest. 2001;119(4):1222-41.

7. Chelluri L, Im KA, Belle SH, Schulz R, Rotondi AJ, Donahoe MP, et al. Longterm mortality and quality of life after prolonged mechanical ventilation. Crit Care Med. 2004;32(1):61-9.

8. Combes A, Costa MA, Trouillet JL, Baudot J, Mokhtari M, Gibert C, et al. Morbidity, mortality, and quality-of-life outcomes of patients requiring $>$ or $=$ 14 days of mechanical ventilation. Crit Care Med. 2003;31(5):1373-81.

9. Dasta JF, McLaughlin TP, Mody SH, Piech CT. Daily cost of an intensive care unit day: the contribution of mechanical ventilation. Crit Care Med. 2005; 33(6):1266-71.

10. Butler JE, Lim J, Gorman RB, Boswell-Ruys C, Saboisky JP, Lee BB, et al. Posterolateral surface electrical stimulation of abdominal expiratory muscles to enhance cough in spinal cord injury. Neurorehabil Neural Repair. 2011; 25(2):158-67. 
11. McBain RA, Boswell-Ruys CL, Lee BB, Gandevia SC, Butler JE. Abdominal muscle training can enhance cough after spinal cord injury. Neurorehabil Neural Repair. 2013;27(9):834-43.

12. McCaughey EJ, Berry HR, McLean AN, Allan DB, Gollee H. Abdominal functional electrical stimulation to assist ventilator weaning in acute tetraplegia: a cohort study. PLoS One. 2015;10(6):e0128589.

13. McCaughey EJ, Borotkanics RJ, Gollee H, Folz RJ, McLachlan AJ. Abdominal functional electrical stimulation to improve respiratory function after spinal cord injury: a systematic review and meta-analysis. Spinal Cord. 2016;54(9): 628-39.

14. Lee BB, Boswell-Ruys C, Butler JE, Gandevia SC. Surface functional electrical stimulation of the abdominal muscles to enhance cough and assist tracheostomy decannulation after high-level spinal cord injury. J Spinal Cord Med. 2008;31(1):78-82.

15. Vorona S, Sabatini U, Al-Maqbali S, Bertoni M, Dres M, Bissett B, et al. Inspiratory muscle rehabilitation in critically ill adults a systematic review and meta-analysis. Ann Am Thorac Soc. 2018;15(6):735-44.

16. Martin AD, Smith BK, Davenport PD, Harman E, Gonzalez-Rothi RJ, Baz M, et al. Inspiratory muscle strength training improves weaning outcome in failure to wean patients: a randomized trial. Crit Care. 2011;15(2):R84.

17. Dall'Acqua AM, Sachetti A, Santos LJ, Lemos FA, Bianchi T, Naue WS, et al. Use of neuromuscular electrical stimulation to preserve the thickness of the abdominal and chest muscles of critically ill patients: a randomized clinical trial. J Rehabil Med. 2017:49:40-8.

18. McCaughey EJ, Boswell-Ruys C, Hudson AL, Gandevia SC, Butler JE. Optimal electrode position for abdominal functional electrical stimulation. J Appl Physiol. 1985;125(4):1062-1068.

19. DiMarco AF, Romaniuk JR, Kowalski KE, Supinski G. Mechanical contribution of expiratory muscles to pressure generation during spinal cord stimulation. J Appl Physiol (1985). 1999;87(4):1433-9.

20. Abu-Khaber HA, Abouelela AMZ, Abdelkarim EM. Effect of electrical muscle stimulation on prevention of ICU acquired muscle weakness and facilitating weaning from mechanical ventilation. Alexandria J Med. 2013;49:309-15.

21. Medrinal C, Combret Y, Prieur G, Robledo Quesada A, Bonnevie T, Gravier $\mathrm{FE}$, et al. Comparison of exercise intensity during four early rehabilitation techniques in sedated and ventilated patients in ICU: a randomised crossover trial. Crit Care. 2018;22(1):110.

22. Routsi C, Gerovasili V, Vasileiadis I, Karatzanos E, Pitsolis T, Tripodaki E, et al. Electrical muscle stimulation prevents critical illness polyneuromyopathy: a randomized parallel intervention trial. Crit Care. 2010;14(2):R74.

23. Doorduin J, Roesthuis LH, Jansen D, van der Hoeven JG, van Hees HWH, Heunks LMA. Respiratory muscle effort during expiration in successful and failed weaning from mechanical ventilation. Anesthesiology. 2018;129(3): 490-501.

24. De Jonghe B, Bastuji-Garin S, Durand MC, Malissin I, Rodrigues P, Cerf C, et al. Respiratory weakness is associated with limb weakness and delayed weaning in critical illness. Crit Care Med. 2007;35(9):2007-15.

25. Jiang C, Esquinas A, Mina B. Evaluation of cough peak expiratory flow as a predictor of successful mechanical ventilation discontinuation: a narrative review of the literature. J Intensive Care. 2017;5:33.

26. Whitehead $\mathrm{AL}$, Julious $\mathrm{SA}$, Cooper $\mathrm{CL}$, Campbell MJ. Estimating the sample size for a pilot randomised trial to minimise the overall trial sample size for the external pilot and main trial for a continuous outcome variable. Stat Methods Med Res. 2016;25:1057-73.

27. Knaus WA, Wagner DP, Draper EA, Zimmerman JE, Bergner M, Bastos PG, et al. The APACHE III prognostic system. Risk prediction of hospital mortality for critically ill hospitalized adults. Chest. 1991;100(6):1619-36.

28. Miller MR, Hankinson J, Brusasco V, Burgos F, Casaburi R, Coates A, et al. Standardisation of spirometry. Eur Respir J. 2005:26(2):319-38.

29. Mallinckrod CH, Lane PW, Schnell D, Peng Y, Mancuso JP. Recommendations for the primary analysis of continuous endpoints in longitudinal clinical trials. Ther. Innov. Regul. Sci. 2008;42:303-19.

30. Gray RJ. A class of K-sample tests for comparing the cumulative incidence of a competing risk. Ann Stat. 1988;16(3):1141-54.

31. Carter HE, Winch S, Barnett AG, Parker M, Gallois C, Willmott L, et al. Incidence, duration and cost of futile treatment in end-of-life hospital admissions to three Australian public-sector tertiary hospitals: a retrospective multicentre cohort study. BMJ Open. 2017;7(10):e017661.

32. Caruso P, Albuquerque AL, Santana PV, Cardenas LZ, Ferreira JG, Prina E, et al. Diagnostic methods to assess inspiratory and expiratory muscle strength. J Bras Pneumol. 2015;41(2):110-23.
33. Beduneau G, Pham T, Schortgen F, Piquilloud L, Zogheib E, Jonas M, et al. Epidemiology of weaning outcome according to a new definition. The WIND Study. Am J Respir Crit Care Med. 2017;195(6):772-83.

34. Goligher EC, Laghi F, Detsky ME, Farias P, Murray A, Brace D, et al. Measuring diaphragm thickness with ultrasound in mechanically ventilated patients: feasibility, reproducibility and validity. Intensive Care Med. 2015; 41(4):642-9.

35. Goligher EC, Dres M, Fan E, Rubenfeld GD, Scales DC, Herridge MS, et al. Mechanical ventilation-induced diaphragm atrophy strongly impacts clinical outcomes. Am J Respir Crit Care Med. 2018;197(2):204-13.

\section{Publisher's Note}

Springer Nature remains neutral with regard to jurisdictional claims in published maps and institutional affiliations.
Ready to submit your research? Choose BMC and benefit from:

- fast, convenient online submission

- thorough peer review by experienced researchers in your field

- rapid publication on acceptance

- support for research data, including large and complex data types

- gold Open Access which fosters wider collaboration and increased citations

- maximum visibility for your research: over $100 \mathrm{M}$ website views per year

At BMC, research is always in progress.

Learn more biomedcentral.com/submissions 